\title{
Memory impairments in humans after acute tryptophan depletion using a novel gelatin-based protein drink
}

Citation for published version (APA):

Sambeth, A., Riedel, W. J., Tillie, D. E., Blokland, A., Postma, A., \& Schmitt, J. A. J. (2009). Memory impairments in humans after acute tryptophan depletion using a novel gelatin-based protein drink. Journal of Psychopharmacology, 23(1), 56-64. https://doi.org/10.1177/0269881108089577

Document status and date:

Published: 01/01/2009

DOI:

10.1177/0269881108089577

Document Version:

Publisher's PDF, also known as Version of record

Document license:

Taverne

Please check the document version of this publication:

- A submitted manuscript is the version of the article upon submission and before peer-review. There can be important differences between the submitted version and the official published version of record.

People interested in the research are advised to contact the author for the final version of the publication, or visit the DOI to the publisher's website.

- The final author version and the galley proof are versions of the publication after peer review.

- The final published version features the final layout of the paper including the volume, issue and page numbers.

Link to publication

\footnotetext{
General rights rights.

- You may freely distribute the URL identifying the publication in the public portal. please follow below link for the End User Agreement:

www.umlib.nl/taverne-license

Take down policy

If you believe that this document breaches copyright please contact us at:

repository@maastrichtuniversity.nl

providing details and we will investigate your claim.
}

Copyright and moral rights for the publications made accessible in the public portal are retained by the authors and/or other copyright owners and it is a condition of accessing publications that users recognise and abide by the legal requirements associated with these

- Users may download and print one copy of any publication from the public portal for the purpose of private study or research.

- You may not further distribute the material or use it for any profit-making activity or commercial gain

If the publication is distributed under the terms of Article $25 \mathrm{fa}$ of the Dutch Copyright Act, indicated by the "Taverne" license above, 


\title{
Memory impairments in humans after acute tryptophan depletion using a novel gelatin-based protein drink
}

\author{
๖ \\ Journal of Psychopharmacology \\ 23(1) (2009) 56-64 \\ () 2009 British Association \\ for Psychopharmacology \\ ISSN 0269-8811 \\ SAGE Publications Ltd, \\ Los Angeles, London, \\ New Delhi and Singapore \\ 10.1177/0269881108089577
}

A Sambeth Faculty of Psychology \& Neuroscience, Department of Neuropsychology and Psychopharmacology, Maastricht University, Maastricht, The Netherlands; Brain \& Behaviour Institute, Maastricht University, Maastricht, The Netherlands.

WJ Riedel Faculty of Psychology \& Neuroscience, Department of Neuropsychology and Psychopharmacology, Maastricht University, Maastricht, The Netherlands; Brain \& Behaviour Institute, Maastricht University, Maastricht, The Netherlands.

DE Tillie Brain \& Behaviour Institute, Maastricht University, Maastricht, The Netherlands.

A Blokland Faculty of Psychology \& Neuroscience, Department of Neuropsychology and Psychopharmacology, Maastricht University, Maastricht, The Netherlands; Brain \& Behaviour Institute, Maastricht University, Maastricht, The Netherlands.

A Postma Experimental Psychology, Helmholtz Institute, Utrecht University, Utrecht, The Netherlands.

JAJ Schmitt Brain \& Behaviour Institute, Maastricht University, Maastricht, The Netherlands.

\begin{abstract}
Acute tryptophan depletion (ATD) can be used to decrease serotonin levels in the brain. Traditionally, ATD has been established by administering amino acid (AA) mixtures and studies using this method showed that serotonin is involved in learning and memory processes. This study used a recently developed gelatin-based protein drink to examine whether it 1) is superior to the traditional AA method in controlling the tryptophan levels in the placebo condition, 2) impairs long-term memory and 3)

differentially affects episodic and spatial memory. Sixteen healthy subjects participated in a double-blind, placebo-controlled study. Memory was assessed using a visual verbal learning test and an object relocation task (spatial memory). Tryptophan ratio significantly decreased after ATD and did not significantly increase in the placebo condition. Delayed recall in
\end{abstract}

the verbal learning test and delayed relocation of objects to positions in the spatial task were impaired after ATD. Spatial short-term memory, however, improved. The current results indicate that the tryptophan levels were essentially neutral in the placebo condition compared with those in the traditional AA mixture. Our study provides further evidence that impairment in long-term episodic and elementary spatial memory after ATD is related to lowered tryptophan levels in plasma.

\section{Key words}

acute tryptophan depletion; episodic memory; gelatin drink; spatial memory

\section{Introduction}

Serotonin does not only influence the regulation of mood but also cognitive processes such as learning and memory (Meneses, 1999; Schmitt, et al., 2006). One method to examine the function of serotonin neurotransmission in the brain is acute tryptophan depletion (ATD). ATD causes a temporary global reduction of serotonin (5-HT) synthesis in the brain by decreasing the availability of its precursor L-tryptophan (TRP) (Moore, et al., 2000; Booij, et al., 2003).

Traditionally ATD has been established using amino acid (AA) mixtures that contained about 15 different AAs, including the five large AAs (LNAAs: tyrosine, phenylalanine, leucine, isoleucine and valine), but no TRP (Young, et al., 1985). In this way, competition between TRP and the LNAAs can be induced at the blood-brain barrier and the uptake of TRP is decreased. Using this method, plasma TRP and brain 5-HT reductions of up to $80-90 \%$ have been found in humans (for a review, see Moore, et al., 2000).

Research using the AA mixture showed that ATD impairs learning (Park, et al., 1994; Rogers, et al., 1999; Murphy, et al., 2002) and long-term episodic memory (Riedel, et al., 1999; Schmitt, et al., 2000; Sobczak, et al., 2002; Harrison, et al., 2004; Kilkens, et al., 2004; Scholtissen, et al., 2006), improves attention processes (Coull, et al., 1995; Schmitt, et al., 2000), and influences the processing of emotional stimuli (Rubinsztein, et al., 2001; Murphy, et al., 2002; Attenburrow, et al., 2003). The traditional AA mixture has also been used in rats to achieve ATD (Brown, et al., 1998; Blokland, et al., 2002). In both reported studies, however, ATD did not affect cognitive behaviour. This discrepancy with human studies is likely because of the fact that ATD only moderately reduced 
plasma TRP, and thus also brain 5-HT, in animals (Brown, et al., 1998; Blokland, et al., 2002).

Recently, an alternative method for ATD was developed (Blokland, et al., 2004). A gelatin-based protein (GP) drink that contained the entire range of amino acids in the form of peptides, but almost completely lacking TRP, was used. It was shown that ATD using the GP drink lowered plasma TRP levels in humans as effective as the traditional AA mixture. Furthermore, plasma TRP levels could effectively be lowered in rats up to 60-75\% (Blokland, et al., 2004; Lieben, et al., 2004a).

Although this has not always been the case (Golightly, et al., 2001; Neumeister, et al., 2004), when using the traditional method, a significant increment of up to $200 \%$ in plasma TRP is frequently found after the intake of the balanced drink used as a placebo (for reviews see: Van der Does, 2001; Fusar-Poli, et al., 2006). This increase may alter performance in the control condition and, therefore, unintentionally affect the outcome of a study. For example, working memory for verbal and affective stimuli is impaired after TRP loading compared with TRP depletion (Luciana, et al., 2001), whereas fear recognition is enhanced after TRP loading (Attenburrow, et al., 2003). An advantage of the GP treatment over the AA mixture is that the GP placebo mixture is essentially neutral with regard to the effects on plasma TRP and the TRP/ LNAA ratio (Blokland, et al., 2004). In this respect, the GP mixture is as effective as the low-dose depletion method that was developed by Krahn et al. to replace the placebo drink (Krahn, et al., 1996; Booij, et al., 2005).

ATD in rats, following intake of the GP drink, significantly decreased plasma TRP, brain TRP and brain 5-HT values (Lieben, et al., 2004a). Furthermore, object memory was impaired in the rats after ATD compared with placebo (Lieben, et al., 2004a; Lieben, et al., 2005). Spatial short-term learning was not affected (Lieben, et al., 2004b), which is in accordance with the lack of an impairment of spatial working memory in humans after the intake of the traditional AA mixture (Park, et al., 1994; Harrison, et al., 2004).

As noted above, 5-HT level in the hippocampus was significantly decreased after ATD using the GP drink in rats (Lieben, et al., 2004a) coming along with an impairment in memory processing (Lieben, et al., 2004b).Van der Veen, et al. (2006) found decreased hippocampal activity after ATD during the encoding phase in an episodic memory task. These joint results suggest a role for hippocampal 5-HT in memory processing. The hippocampus has previously not only been linked to declarative but also to (long-term) spatial memory processes (for reviews see e.g. Eichenbaum, et al., 1999; Burgess, et al., 2002; Moscovitch, et al., 2006). Even though spatial working memory was not affected by ATD in rats (Lieben, et al., 2004b) and humans (Park, et al., 1994; Riedel, et al., 1999; Luciana, et al., 2001; Hughes, et al., 2003; Harrison, et al., 2004; Porter, et al., 2005), the fact that 5-HT plays a role in functioning of the hippocampus suggests that ATD might also affect spatial memory. Possibly, long-term spatial memory could be selectively affected, as ATD previously mainly impaired long-term memory processes. Therefore, in this study, we assessed both short- and long-term spatial memory performances in an object relocation task (Postma and de Haan, 1996). This task differentiates between 1) assignment of an object to a relative position, 2) the memory of positions per se and 3) linking object to exact or coordinate positions (Kessels, et al., 1999).

So far, the only study in humans using the GP drink failed to show an impairing effect of ATD on the accuracy of longterm memory (Evers, et al., 2005), in contrast to studies using the traditional AA mixture (e.g. Riedel, et al., 1999; Schmitt, et al., 2000). Only the speed of delayed word recognition in a verbal learning test was reduced (Evers, et al., 2005). In the study by Evers et al., cognitive tests were performed between 3 and $4 \mathrm{~h}$ after intake of the GP meal, although 4-7 h intervals were used in the studies showing ATD-induced impairment of consolidated declarative memory. The reason for the delay between the trough of TRP blood levels at $4 \mathrm{~h}$ after administration and peak behavioural effect at $\sim 6 \mathrm{~h}$ after administration is thought to reflect the time necessary to elapse between peripheral TRP depletion and the lowering of available 5-HT in the brain. ATD is thought to affect 5-HT synthesis, therefore available 5-HT in the brain needs to be released before an inhibition of 5-HT synthesis in the brain can become manifest in this case in a memory task. Evers, et al. (2005) assumed that the metabolism of the GP drink was faster than that of the AA drink and hence started their effect-measures at $3 \mathrm{~h}$ after administration. This is possibly why they missed the predicted memory impairments, because this did not take fully into account the abovementioned delay.

The aim of the current study was to examine whether the novel ATD method does produce profound effects on verbal and spatial memory between 4 and $5 \mathrm{~h}$ after intake of the GP meal in healthy volunteers. A further aim was to assess differential effects of ATD on verbal and spatial memory. To this end, we used a visual verbal learning test and an object relocation task.

\section{Methods}

\section{Subjects}

Sixteen healthy subjects participated in this study, of which 13 (five men and eight women, mean age 21.8) completed the experiment. They had all completed secondary education.

Before participation, physical and mental health of each of the participants was checked using a health questionnaire. Exclusion criteria were a history of cardiac, hepatic, renal, pulmonary, neurological, gastrointestinal, haematological or psychiatric illness. Other criteria were a family history of depression, excessive drinking (>20 units of alcohol per week), pregnancy or lactation, use of medication other than oral contraceptives and any sensory or motor deficits, which could reasonably be expected to affect the performance during the tests.

The study was approved by the Medical Ethics Committee of Maastricht University and all participants gave their written 
informed consent before participation. The subjects, who were recruited through advertisements at Maastricht University, were paid for their participation.

\section{Design}

The study was conducted using a placebo-controlled, doubleblind, cross-over design. The treatment consisted of a GP meal to induce ATD (see below) or a placebo. The treatment order was balanced over 2 days, which were separated by at least 7 days.

\section{Treatment}

The GP drink was kindly provided by PB Gelatins (Tessenderlo, Belgium). The amino acid composition of the drink can be found in Table 1. The drink was prepared mixing $100 \mathrm{~g}$ of the GP with $200 \mathrm{~mL}$ water. The placebo consisted of the identical composition to which $1.21 \mathrm{~g}$ L-TRP (Sigma, Zwijndrecht, The Netherlands) was added. The two drinks had an identical taste.

\section{Procedure}

After enrolment in the study, the subjects first participated in a training session. During this session all cognitive tests were practiced to familiarize the subjects with the study procedures and minimize procedural learning effects.

On the day before each test day, the use of alcohol was prohibited. The use of recreational drugs was prohibited from 2 weeks before the first session until the end of the study. Smoking was prohibited during the test day. Participants were instructed to arrive at the laboratory well-rested (following a

Table 1 Composition ( $\mathrm{g}$ ) of the natural gelatin-based protein meal in $200 \mathrm{~mL}$ tap water

\begin{tabular}{lr}
\hline Aspartic acid + asparagines & 5.2 \\
Glutamic acid + glutamine & 9.3 \\
Hydroxyproline & 12.1 \\
Serine & 3.1 \\
Glycine & 22.5 \\
Histidine & 0.5 \\
Arginine & 8.8 \\
Threonine & 1.1 \\
Alanine & 9.3 \\
Proline & 13.3 \\
Tyrosine & 0.4 \\
Valine & 2.1 \\
Methionine & 0.6 \\
Cysteine & 0.2 \\
Isoleucine & 1.4 \\
Leucine & 3.0 \\
Hydroxylysine & 1.4 \\
Phenylalanine & 1.9 \\
Tryptophan & 0.1 \\
Lysine & 3.6 \\
\hline
\end{tabular}

As can be seen, tryptophan is almost completely lacking in the mixture. normal night's sleep), after an overnight fast (except water) starting at 10.00 p.m. One cup of coffee or tea (without milk or sugar) was allowed on the morning of the test day to prevent possible caffeine withdrawal effects. Female subjects were tested in the follicular phase of the menstrual cycle.

Upon arrival, subjects performed the cognitive tests and filled in the questionnaires, which lasted about $1 \mathrm{~h}(\mathrm{~T}-1)$. Then, after a baseline blood sample was taken, they received the protein drink, which has to be consumed within $15 \mathrm{~min}$. During the ensuing $4 \mathrm{~h}$, the participants remained at the specially equipped laboratory room, where they could watch television, read or play board games. Two hours after start of the treatment, subjects received a low-TRP and low-protein lunch. Four hours after treatment (T4), the second assessment (cognition, mood and blood sample) was conducted. Note that the blood sample was taken approximately $5 \mathrm{~h}$ after treatment (T5). The order of task presentation can be found in Table 2.

\section{Tasks}

The visual verbal learning test This test is an adapted version of the Rey Auditory Verbal Learning Test (Rey, 1964; Riedel, et al., 1999) and assesses declarative episodic memory. The test consisted of a list of 30 monosyllabic words (18 nouns and 12 adjectives) in Dutch, which were presented in three trials on a computer screen. Items were presented in the same sequence at a rate of one per $2 \mathrm{~s}$. Each trial ended with a free recall of the words (immediate recall). Thirty minutes after the third trial, the subject was requested to recall as many words as possible (delayed recall). A yes/no recognition test, consisting of 15 former words and 15 new but comparable words, was given after the delayed recall test. The words remained on the screen for $2000 \mathrm{~ms}$ or until the subject responded. Another $1000 \mathrm{~ms}$ elapsed before the next word appeared on the screen. After presentation of each word, the subject had to respond 'YES/NO'

Table 2 Order of task presentation

\begin{tabular}{ll}
\hline $\begin{array}{l}\text { Time from } \\
\text { start (min) }\end{array}$ & Task \\
\hline 0 & $\begin{array}{l}\text { Visual verbal learning task } \\
\text { Immediate recall } \\
\text { Facial emotions task (not presented in this article) }\end{array}$ \\
8 & $\begin{array}{l}\text { Visual verbal learning task } \\
\text { Delayed recall }\end{array}$ \\
30 & Delayed recognition \\
& Object relocation task \\
35 & Immediate condition, both OTP and COM \\
40 & Continuous performance test \\
50 & Questionnaires \\
60 & Object relocation task \\
& Delayed condition, both OTP and COM
\end{tabular}

OTP, object-to-position; COM, combined. 
as fast as possible to indicate recognition of the word (delayed recognition). The reaction times (RTs) were recorded.

According to the theory of signal detection (Pollack and Norman, 1964), the proportion of correctly recognized words (cr) and the proportion of falsely recognized (fr) constitute the nonparametric sensitivity measure: $A^{\prime}=1-1 / 4(\mathrm{fr} / \mathrm{cr}+(1-\mathrm{cr}) /(1-\mathrm{fr}))$. $A^{\prime}$ is in fact the proportion of correctly recognized words, corrected for the subject's response tendency. Because the distribution of $A^{\prime}$ is skewed due to a ceiling effect, A' should be arcsine transformed before being used in statistical analysis.

The outcome variables used were the total number of words recalled after the first three trials as a measure of short-term memory, the number of correct words on delayed free recall as a measure of retrieval from long-term memory, A' as a measure of storage in long-term memory and the median RT of correctly recognized target words as a measure of speed of long-term memory. In each of the assessments, a different word list was presented. The lists were comparable with regard to their level of abstraction and the affective tone of the words. Parallel lists were order balanced over assessments.

The object relocation test The object relocation test assesses spatial memory (Kessels, et al., 1999). The present task consisted of two subtasks, an object-to-position (OTP) and a combined (COM) task.

In an experimental trial, a square frame containing 10 objects was presented for $30 \mathrm{~s}$ on a computer screen. The objects then disappeared from the square and reappeared above it. Participants could select an object with the computer mouse and place it back into the square. In the first OTP assignment condition, the positions were marked by black dots and the objects were to be assigned to their previous position (immediate relocation OTP). In a second separate condition (COM), the participant had to place a set of new objects in their original position as accurately as possible without premarked dots (immediate relocation COM). Approximately 30 min later, both the OTP and the COM tasks were performed again. Only this time, the objects were immediately placed above the square and participants had to either place them on the dots (OTP) or as accurately as possible within the square $(\mathrm{COM})$. There were no time limits for the relocation phase. The COM condition always followed the OTP condition.

All objects were coloured pictures $( \pm 1 \times 1 \mathrm{~cm})$ of everyday, easy-to-name objects. For each OTP and COM sessions, a different set of stimuli was subsequently presented with different sets of objects and spatial layouts. In total, 10 sets of objects existed and the sets were comparable (e.g., in colour). The order of the parallel lists was balanced over assessments.

Outcome variables were number of errors made at replacing objects for the OTP and COM conditions (assignment of an object to a position). In the OTP condition, percentage of correctly relocated object was computed. Arguably this measure reflects object to (relative or categorical) location binding, a global code of an object's structure. For the COM task, an absolute displacement error was calculated as the total of the absolute distance between the relocated position and the original position for each object. It has been suggested that this measure reflects another aspect of binding objects to locations - linking objects to exact or coordinate positions. It is unclear whether this is really a separate form of binding (cf. Van Asselen, et al., 2008). Finally, the ability to remember the locations per se, independent from the ability to remember which object was in each location, was examined by computing a positional best-fit score (i.e., the assignment of original to relocated positions which yields the smallest distance error for the stimulus as a whole).

Continuous performance test This test measures vigilance and the possibility to withhold a response (Umbricht, et al., 2003). Letters (A, E, H, L, K and X) were presented on a computer screen one after the other. The duration of the letter presentation was $150 \mathrm{~ms}$, which was followed by an inter-stimulus interval of $750 \mathrm{~ms}$. The instruction was to press the spacebar as soon as the letter ' $A$ ' was followed by an ' $\mathrm{X}$ '. In all other cases, no response was required. In total, 48 trials were presented to which a response had to be made.

The outcome variables were the number of correct responses, the number of false alarms, the number of misses, the median reaction time at correct responses, d' (sensitivity measure) and $\beta$ (response bias measure).

\section{Questionnaires}

Mood was assessed using the Bond and Lader Visual Analogue Scale (Bond and Lader, 1974) and a visual analogue version of the profile of mood states (POMS, McNair, et al., 1971). The questionnaires both consisted of bipolar sets of adjectives, which measured 1) alertness, contentment, and calmness (Bond and Lader) and 2) the dimensions anger, depression, fatigue, tension and vigour (POMS). The items were scored on a $0-100 \mathrm{~mm}$ scale. When the participants felt as they normally do, they were asked to mark the middle of the line (50).

Adverse effects, using 31 items such as headache or nausea, were registered and scored on a 5-point scale from 'no complaint at all' (0) to 'severe complaint' (4).

\section{Blood samples}

Blood $(10 \mathrm{~mL})$ was collected by venepuncture in sodium heparin tubes. After collection, the blood samples were immediately placed on ice and then centrifuged at $4{ }^{\circ} \mathrm{C}(10 \mathrm{~min}$ at $4000 \mathrm{rpm}$ ). Subsequently, $100 \mu \mathrm{L}$ of plasma was mixed with $8 \mathrm{mg}$ of sulphasalicyl acid and frozen at $-80^{\circ} \mathrm{C}$ until the amino acid analysis was performed (van Eijk, et al., 1993). The total plasma TRP level and the TRP/ 2 LNAA ratio was calculated.

\section{Statistical analysis}

The outcome variables of the cognitive and mood assessments, as well as the total number of adverse effects, were analysed using a repeated-measures analysis of variance (ANOVA) with treatment (ATD versus placebo) and time (T-1 vs T4) as 
a within factor. If a significant interaction was found, an ANOVA was performed for T-1 and T4 separately.

\section{Results}

Baseline performance (T-1) on the cognitive tests did not differ on the two testing days, except for the absolute error score in the COM condition of object relocation (both immediate and delayed relocation; see Table 3 ). These effects are because of an interaction between treatment and order of treatment $(F(1,11)=10.74$, $P=0.007$ and $F(1,11)=14.19, P=0.003$, for immediate and delayed, respectively). Order of treatment did not affect the results at $\mathrm{T} 4(F(1,11)=0.10$, n.s. and $F(1,11)=0.83$, n.s., for immediate and delayed, respectively).

\section{Missing data}

Two female participants did not finish the study. One of them complained of nausea and had to throw up during the placebo condition. The other participant did not return for the second session after she had had tryptophan depletion during the first. A third female participant was excluded from analysis because she had to throw up during the placebo condition and showed complaints of nausea at T4. Consequently, the data of 13 sub- jects were used for the statistical analysis. Two of the missing participants had received a placebo on the first test day, whereas the other one started with ATD.

Blood samples were missing from two participants.

\section{Blood samples}

In the depletion condition, plasma TRP was significantly reduced by $60 \%$ at T5 compared with baseline $(F(1,12)=97.03$, $P<0.001)$ and the TRP $/ \Sigma$ LNAA ratio was reduced by $63 \%$ at T5 $(F(1,12)=159.84, P<0.001)$, as can be seen in Figure 1 . Total plasma TRP was significantly increased by $36 \%$ at T5 compared with baseline $(F(1,12)=7.41, P=0.02)$ in the placebo condition and the TRP/ LLNAA ratio was non-significantly increased by $24 \%$ at $\mathrm{T} 5$.

\section{Visual verbal learning test}

The results of the four dependent measures of the verbal learning task are summarized in Table 3 and illustrated in Figure 2. ATD did not affect the total number of words remembered during immediate recall. An interaction was found between Treatment and Time $(F(1,12)=6.08, P=0.030)$. The ANOVA for T4 only showed that the participants recalled fewer words at delayed recall in the depletion condition com-

Table 3 Mean scores (standard errors, SE) for the outcome variables of the visual verbal learning task, the object relocation task and the continuous performance test for the ATD and placebo conditions, at baseline (T-1) and $4 \mathrm{~h}$ after the intake of the meal (T4)

\begin{tabular}{|c|c|c|c|c|}
\hline & \multicolumn{2}{|c|}{ ATD condition } & \multicolumn{2}{|c|}{ Placebo condition } \\
\hline & $\mathrm{T}-1$ & T4 & $\mathrm{T}-1$ & $\mathrm{~T} 4$ \\
\hline \multicolumn{5}{|l|}{ Visual verbal learning task } \\
\hline Immediate recall: total number of words recalled (over three trials) & $47.0(3.9)$ & $41.3(2.6)$ & $49.1(3.5)$ & $45.2(3.5)$ \\
\hline Delayed recall & $17.1(1.6)$ & $12.8(1.3)$ & $16.2(1.8)$ & $15.7(1.8)^{\mathrm{a}}$ \\
\hline Delayed recognition: number of words correctly recognized & $27.2(0.7)$ & $26.5(0.7)$ & $26.8(0.7)$ & $26.2(0.8)$ \\
\hline Delayed recognition sensitivity: $A^{\prime}$ & $0.97(0.01)$ & $0.97(0.01)$ & $0.97(0.01)$ & $0.96(0.01)$ \\
\hline Delayed recognition: reaction time (in ms) & $720.7(26.4)$ & $726(33.1)$ & $700.4(25.2)$ & $728(24.7)$ \\
\hline \multicolumn{5}{|l|}{ Object relocation } \\
\hline OTP immediate: number of errors & $1.0(0.4)$ & $1.0(0.4)$ & $0.2(0.2)$ & $1.0(0.4)$ \\
\hline OTP delayed: number of errors & $1.3(0.4)$ & $3.2(0.8)$ & $1.7(0.8)$ & $1.7(0.6)^{\mathrm{a}}$ \\
\hline COM immediate: number of errors & $2.4(0.6)$ & $1.4(0.3)$ & $0.7(0.4)$ & $1.5(0.6)$ \\
\hline COM immediate: absolute error & $142.3(29.5)$ & $116.9(22.0)$ & $93.4(21.4)$ & $162.6(30.4)^{\mathrm{a}}$ \\
\hline COM immediate: best fit & $104.6(12.9)$ & $90.9(11.5)$ & $81.8(14.1)$ & $104.9(17.4)$ \\
\hline COM delayed: number of errors & $2.8(0.7)$ & $3.2(0.7)$ & $1.7(0.5)$ & $2.7(0.7)$ \\
\hline COM delayed: absolute error & $180.7(31.5)$ & $150.8(41.9)$ & $123.2(20.1)$ & $193.2(42.2)$ \\
\hline COM delayed: best fit & $118.4(12.5)$ & $100.3(14.5)$ & $102.7(14.6)$ & $124.2(18.5)$ \\
\hline \multicolumn{5}{|l|}{ Continuous performance test } \\
\hline Correct responses & $46.8(0.4)$ & $46.2(0.7)$ & $46.5(0.5)$ & $46.6(0.5)$ \\
\hline False alarms & $0.9(0.5)$ & $0.4(0.1)$ & $0.9(0.3)$ & $0.4(0.2)$ \\
\hline Misses & $1.2(0.4)$ & $1.7(0.7)$ & $1.5(0.5)$ & $1.3(0.5)$ \\
\hline Reaction time at correct responses (in ms) & $405.2(17.7)$ & $400.9(14.8)$ & $410.2(17.0)$ & $388.9(13.0)$ \\
\hline $\mathrm{D}^{\prime}$ & $6.49(0.62)$ & $5.94(0.55)$ & $5.65(0.57)$ & $6.61(0.51)$ \\
\hline$\beta$ & $2.25(1.04)$ & $2.46(1.03)$ & $0.68(1.31)$ & $2.38(1.30)$ \\
\hline
\end{tabular}

ATD, acute tryptophan depletion; OTP, object-to-position; COM, combined. aTreatment effect, $P<0.05$. 


\section{Ratio TRP/ $/$ LNAA}

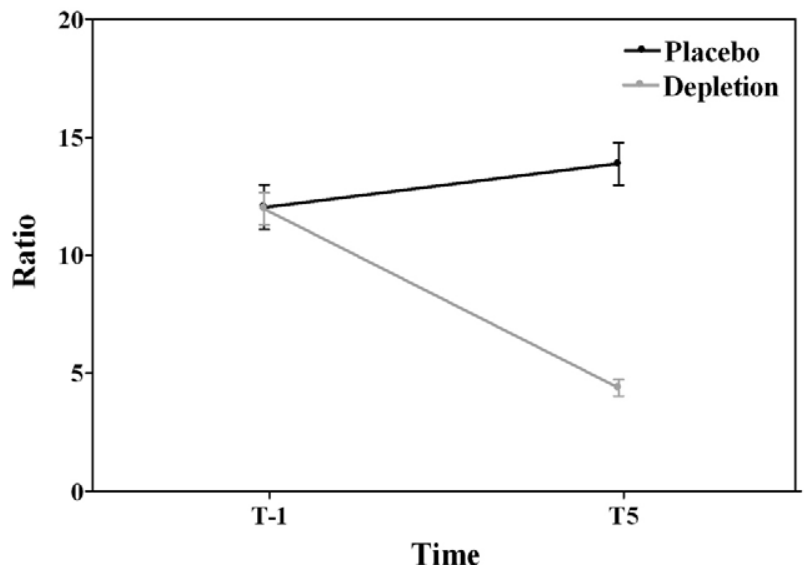

Plasma tryptophan

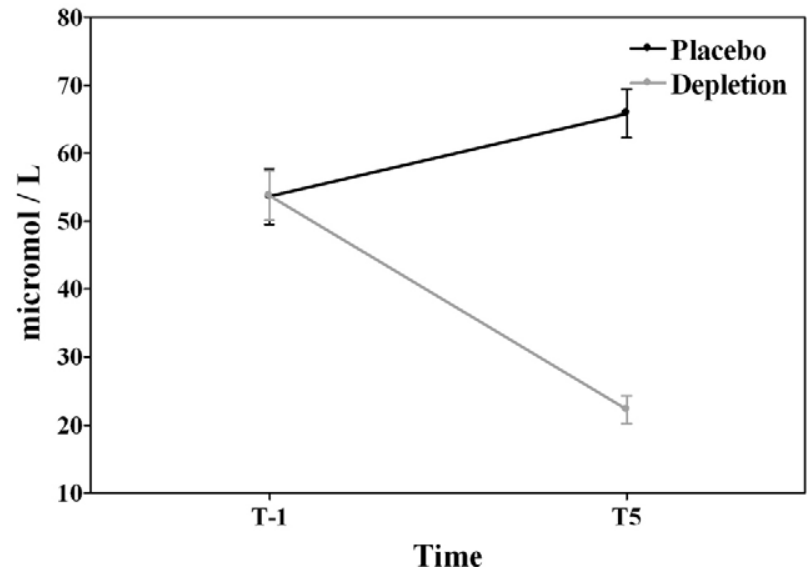

Figure 1 The mean and SE of the blood plasma levels of TRP and the ratio between TRP and the other large amino acids (TRP/ $\Sigma$ LNAA) at baseline (T-1) and $5 \mathrm{~h}$ after treatment (T5). ATD significantly decreased the TRP level and ratio compared with the placebo $5 \mathrm{~h}$ after intake of the drink.

pared to the placebo condition $(F(1,12)=7.29, P=0.019)$. None of the measures of the delayed recognition, sensitivity and the RT of correct responses, showed any significant effects (F's $<1$, n.s.).

\section{Object relocation test}

The results of the immediate and delayed relocation can be found in Table 3 and Figure 3. With regard to the OTP, no significant differences were found between the ATD and the placebo condition for the number of correct relocations during immediate relocation $\left(F^{\prime} s<2\right.$, n.s.). However, an

\section{Verbal learning task}

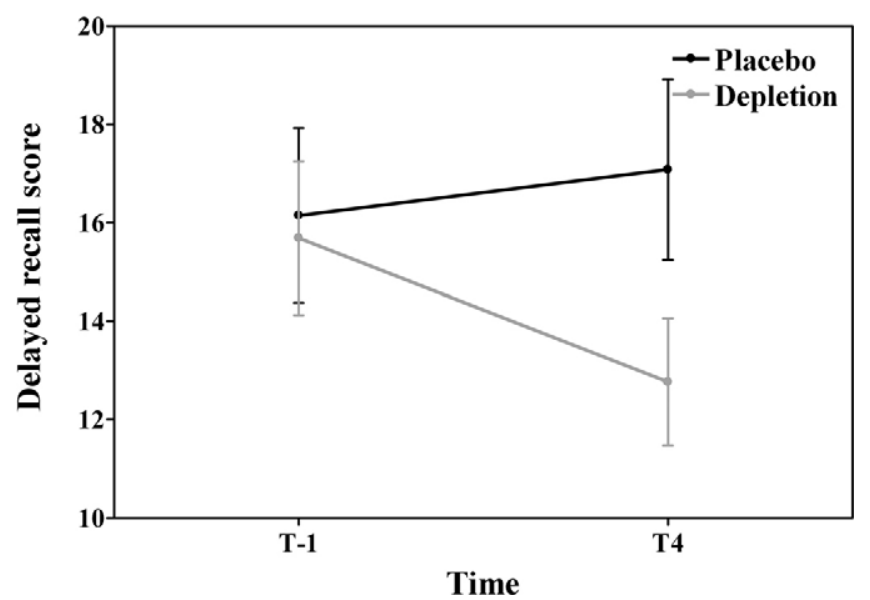

Figure 2 The mean and SE of the delayed recall score at baseline (T-1) and $4 \mathrm{~h}$ after treatment (T4). Recall was significantly impaired after ATD compared with the placebo condition at T4.
ANOVA showed an interaction between Treatment and Time $(F(1,12)=6.50, P=0.025)$. The ANOVA for Treatment only at $\mathrm{T} 4$ showed that participants made more errors replacing items after ATD compared with placebo at the delayed relocation $(F(1,12)=6.94, P=0.022)$.

In the COM condition, an interaction between Treatment and Time was found $(F(1,12)=17.10, P=0.001)$ with regard to the absolute error score at immediate relocation. Participants had a lower error score after ATD than after placebo at T4 and thus performed better after $\operatorname{ATD}(F(1,12)=5.236$, $P=0.041)$. With regard to the delayed relocation, an interaction between Treatment and Time was found as well

\section{Delayed relocation of Object-to-position task}

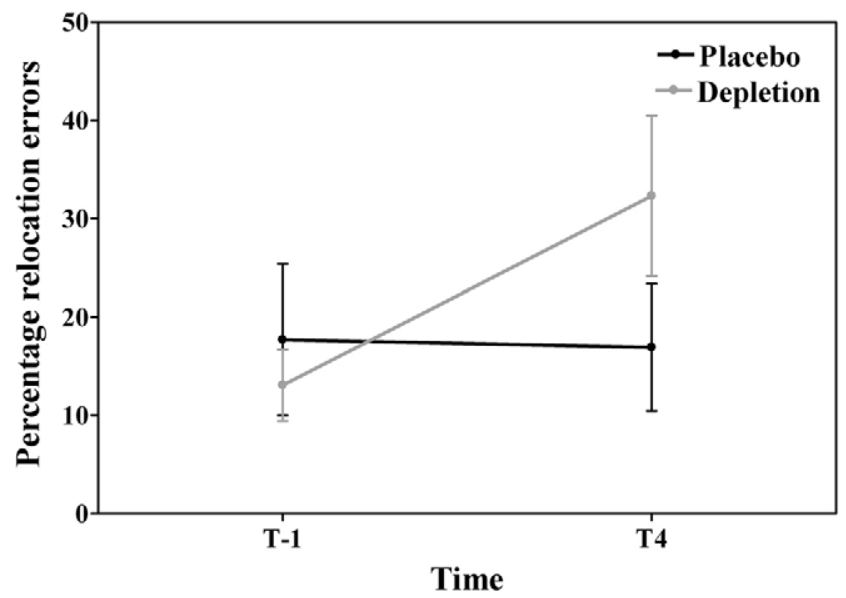

Figure 3 The mean and SE of the percentage errors made in the delayed OTP condition at baseline (T-1) and $4 \mathrm{~h}$ after treatment (T4). Delayed relocation was significantly impaired by the ATD treatment. 
$(F(1,12)=12.56, P=0.004)$. However, the ANOVA for Treatment did not show any significant effects $\left(F^{\prime}\right.$ s $<2$, n.s.).

The best-fit score did not differ between the ATD and placebo condition at both immediate and delayed relocation $\left(F^{\prime}\right.$ s $<4.3$, n.s. $)$.

\section{Continuous performance test}

The results of the continuous performance test are summarized in Table 3. Although an interaction was found between Treatment and Time with regard to the RTs $(F(1,12)=5.125$, $P=0.043$ ), none of the measures of the continuous performance test showed any significant differences between the ATD and placebo conditions at T4 ( $F$ 's $<1$, n.s.).

\section{Mood scales and adverse effects}

In general, the ratings on the POMS, the Bond and Lader, and the adverse effects closely resembled the results of Evers, et al. (2005), except for the fact that two female participants were excluded from analysis because of feelings of nausea and the incidence of vomiting. One female participant decided not to return after the first placebo measurement without stating any reason.

None of the scales of the POMS and the Bond and Lader showed any significant differences between the times of measurement or between treatments. In general, the complaints after intake of both the placebo and ATD meals were sleepiness, light nausea and diarrhoea. However, participants did not significantly report more physical complaints after ATD compared with placebo, or after the drink compared with baseline.

Because changes in mood could cause changes in responding during the tasks, correlations were calculated between the POMS (mood, vigour, fatigue, anger and tension) scores and the total immediate recall and delayed recall scores of the verbal learning task, as well as the delayed relocation during the OTP of the object relocation task. These correlations were calculated for responses from T4. None of the five measures of the POMS significantly correlated with the scores of the verbal learning or object relocation task $(P>0.14)$.

\section{Discussion}

This study examined the effects of a novel ATD method on memory processing in healthy adults using the visual verbal learning test and a spatial object relocation task. The plasma TRP levels were decreased after ATD by $60 \%$, whereas the ratio was decreased by $63 \%$. Long-term memory was impaired after ATD, as showed by decreased delayed recall scores in the verbal learning task and by the increment in the number of errors at delayed relocation in the spatial task. Remarkably, ATD resulted in a lower absolute error score for the immediate relocation in the COM condition suggesting an improved spatial memory after ATD. Attention performance was not affected by ATD.
One previous study examined the effects of ATD using the GP drink in healthy participants and showed that plasma TRP levels were significantly decreased after ATD $(82 \%$ decrement in TRP/ $/$ LNAA ratio $4 \mathrm{~h}$ after treatment) compared with placebo (Evers, et al., 2005). The current study showed somewhat smaller but similar effects, which are probably caused by the fact that in our study, plasma TRP levels were determined $5 \mathrm{~h}$ after the intake of the drink, whereas Evers et al. determined TRP levels at T4. Possibly, TRP values go back to baseline faster using the GP drink than when using AA mixtures. Nevertheless, the present study indicates that the GP drink is as efficient in lowering plasma TRP as the traditional AA mixtures (Moore, et al., 2000, Blokland, et al., 2004).

Previous ATD studies using the AA mixture frequently showed a significant increase in TRP plasma of up to $200 \%$ in the placebo condition (for review see: Van der Does, 2001; Fusar-Poli, et al., 2006). This may unintentionally have affected the outcome of those studies, because TRP loading significantly affects working memory and face recognition (Luciana, et al., 2001; Attenburrow, et al., 2003). Even though the TRP level in the plasma was significantly increased after treatment with the balanced drink in the current study, this increment was rather small compared with previous ATD studies, and furthermore, the ratio of TRP and other large amino acids did not increase significantly. Thus, the GP drink is more effective in maintaining a stable placebo condition. One study, in which the AA mixture was used to assess memory effects of ATD, provided participants with additional $33 \mathrm{~g}$ fat and $63 \mathrm{~g}$ carbohydrates (Riedel, et al., 1999). In that study, TRP plasma concentrations in the placebo condition were comparable with those found in our study, indicating that both procedures are equally effective in maintaining a constant placebo condition.

It must be noted that the decrements in TRP values were smaller than those mainly found when using the traditional measure. This might seem to be a possible limitation of this study. However, we showed that ATD impaired the delayed recall of words in the verbal learning task. This finding is comparable with previous AA studies reporting that long-term memory is poorer after ATD (e.g. Riedel, et al., 1999, Schmitt, et al., 2000) and may indicate that TRP decrements of about $60 \%$ are sufficient to impair memory performance. Considering the fact that the way in which tryptophan depletion is established differs considerably between the traditional AA mixtures and the current GP drink (Blokland, et al., 2004), the current data provide strong evidence that the memory impairments are indeed related to a decrease in TRP.

Previous studies have shown that ATD does not affect spatial working memory (Park, et al., 1994; Riedel, et al., 1999; Luciana, et al., 2001; Hughes, et al., 2003; Harrison, et al., 2004; Porter, et al., 2005). However, because ATD decreases 5-HT levels in the hippocampus (Lieben, et al., 2004a) and as the hippocampus plays a role in spatial memory, it is possible that, for example, long-term spatial memory is affected by ATD. Therefore, additional to the verbal learning test, we applied an object relocation task in this study to study possible effects of ATD on long-term spatial memory. Using this object 
relocation task, three separate spatial processes can be assessed (see also: Kessels, et al., 1999): 1) the assignment of an object to a relative position, which relies strongly on global, categorical information, 2) the memory of positions per se, independent from the ability to remember which object was in each location and 3) linking objects to exact or coordinate positions.

We found that ATD impaired the delayed relocation in the OTP task, meaning that participants made more errors placing the objects on the pre-marked dots. OTP assignment is likely to be sensitive to verbal interference, which suggests that this process contains a verbal component (Postma and de Haan, 1996). The current result, therefore, is in accordance with the outcome of the visual verbal learning test in the present study and may at least partly reflect an impairment of long-term episodic memory. It may also reflect an impairment in the processing of categorical spatial information, that is, the global position code of an object. Remarkably, delayed relocation in the COM condition was not impaired, indicating that spatial memory for the more precise, metrical position of an object is not impaired by ATD. Further experiments are required to explain these differential effects.

The findings of an impairment in both episodic (verbal learning task) and elementary spatial (object relocation) longterm memory suggest that ATD affects memory on a basic, elementary level, independent from stimulus type. This is in agreement with previous research showing that ATD affects long-term memory for visual verbal stimuli (e.g. Riedel, et al., 1999), auditory verbal stimuli (Porter, et al., 2005), pictures (Sobczak, et al., 2002) and abstract visual patterns (Rubinsztein, et al., 2001).

Intriguingly, ATD decreased the absolute errors in the COM condition of the object relocation task, in particular for the immediate relocation. Considering that OTP appointment was impaired by ATD, this would suggest that categorical binding as measured in the OTP condition involves a different mechanism than coordinate binding in the COM condition. As yet, we can only speculate about the neurophysiological underpinnings of these binding mechanisms and the differential ATD effects. It has been suggested that potentially different neural circuitries are at stake (Kessels, et al., 2000; Kessels, et al., 2002). Functionally, it seems that the improvement in absolute errors is due to an ATD enhancement in the processing of more exact positional information at the shorter time range.

In conclusion, we showed that the GP meal decreased plasma TRP levels and impaired long-term memory in similar ways, as does the traditional AA mixture. Furthermore, we showed that the new ATD method was able to provide a very stable placebo condition, as compared with studies using the traditional AA method. The present results provide evidence for the fact that memory impairments after ATD are indeed because of a change in the availability of TRP. Additionally, the results are in accordance with the fact that ATD affects basic features of long-term memory and is stimulus independent. Further research is needed to clarify the differential effects of ATD on short- and long-term spatial memory functions.

\section{Acknowledgements}

The study was entirely paid by, and carried out at, Maastricht University. At times during the study, WJR has been employed by GlaxoSmithKline R\&D, Cambridge, UK and is now employed by Hoffman-LaRoche R\&D, Basel, Switzerland while remaining affiliated to Maastricht University. JAJS is now employed by Nestlé Research Centre, Lausanne, Switzerland.

\section{References}

Attenburrow, MJ, Williams, C, Odontiadis, J, Reed, A, Powell, J, Cowen, PJ, Harmer, CJ (2003) Acute administration of nutritionally sourced tryptophan increases fear recognition. Psychopharmacology (Berl) 169: 104-107.

Blokland, A, Lieben, C, Deutz, NE (2002) Anxiogenic and depressivelike effects, but no cognitive deficits, after repeated moderate tryptophan depletion in the rat. J Psychopharmacol 16: 39-49.

Blokland, A, Lieben, CK, Deutz, NE, Schmitt, JA (2004) Acute Tryptophan depletion: comparing the effects of an amino acid mixture with a gelatin-based protein in man and rats. Curr Topics Nutraceutical Res 2: 1-8.

Bond, A, Lader, M (1974) The use of visual analogue scales in rating subjective feelings. Brit J Med Psychol 80: 1-46.

Booij, L, Van der Does, AJ, Riedel, WJ (2003) Monoamine depletion in psychiatric and healthy populations: review. Mol Psychiatry 8: 951-973.

Booij, L, Van der Does, AJW, Haffmans, PMJ, Riedel, WJ, Fekkes, D, Blom, MJB (2005) The Effects of High-Dose and Low-Dose Tryptophan Depletion on Mood and Cognitive Functions of Remitted Depressed Patients Journal of Psychopharmacology 19: 267-275.

Brown, CM, Fletcher, PJ, Coscina, DV (1998) Acute amino acid loads that deplete brain serotonin fail to alter behavior. Pharmacol Biochem Behav 59: 115-121.

Burgess, N, Maguire, EA, O'Keefe, J (2002) The human hippocampus and spatial and episodic memory. Neuron 35: 625-641.

Coull, JT, Sahakian, BJ, Middleton, HC, Young, AH, Park, SB, McShane, RH, Cowen, PJ, Robbins, TW (1995) Differential effects of clonidine, haloperidol, diazepam and tryptophan depletion on focused attention and attentional search. Psychopharmacology (Berl) 121: 222-230.

Eichenbaum, H, Dudchenko, P, Wood, E, Shapiro, M, Tanila, H (1999) The hippocampus, memory, and place cells: Is it spatial memory or a memory space? Neuron 23: 209-226.

Evers, EA, Tillie, DE, van der Veen, FM, Lieben, CK, Jolles, J, Deutz, NE, Schmitt, JA (2005) Effects of a novel method of acute tryptophan depletion on plasma tryptophan and cognitive performance in healthy volunteers. Psychopharmacology (Berl) 178: 92-99.

Fusar-Poli, P, Allen, P, McGuire, P, Placentino, A, Cortesi, M, Perez, J (2006) Neuroimaging and electrophysiological studies of the effects of acute tryptophan depletion: a systematic review of the literature. Psychopharmacology (Berl) 188: 131-143.

Golightly, KL, Lloyd, JA, Hobson, JE, Gallagher, P, Mercer, G, Young, AH (2001) acute tryptophan depletion in schizophrenia. Psychol Med 31: 75-84.

Harrison, BJ, Olver, JS, Norman, TR, Burrows, GD, Wesnes, KA, Nathan, PJ (2004) Selective effects of acute serotonin and catecholamine depletion on memory in healthy women. J Psychopharmacol 18: $32-40$. 
Hughes, JH, Gallagher, P, Stewart, ME, Matthews, D, Kelly, TP, Young, AH (2003) The effects of acute tryptophan depletion on neuropsychological function. J Psychopharmacol 17: 300-309.

Kessels, RPC, de Haan, EHF, Kappelle, LJ, Postma, A (2002) Selective impairments in spatial memory after ischaemic stroke. J Clin Exp Neuropsychol 24: 115-129.

Kessels, RP, Postma, A, de Haan, EH (1999) Object Relocation: a program for setting up, running, and analyzing experiments on memory for object locations. Behav Res Methods Instrum Comput 31: 423-428.

Kessels, RPC, Postma, A, Kappelle, LJ, de Haan, EHF (2000) Spatial memory impairment in patients after tumor resection: evidence for a double dissociation. J Neurol Neurosurg Psychiatry 69: 389-391.

Kilkens, TO, Honig, A, van Nieuwenhoven, MA, Riedel, WJ, Brummer, RJ (2004) Acute tryptophan depletion affects brain-gut responses in irritable bowel syndrome patients and controls. Gut 53: 1794-1800.

Krahn, LE, Lu, PY, Klee, G, Delgado, PR, Lin, S-C, Zimmermann, RC (1996) Examining serotonin function: a modified technique for rapid tryptophan depletion Neuropsychopharmacol 15: 325-328.

Lieben, CK, Blokland, A, Sik, A, Sung, E, van Nieuwenhuizen, P, Schreiber, R (2005) The selective 5-HT6 receptor antagonist Ro4368554 restores memory performance in cholinergic and serotonergic models of memory deficiency in the rat. Neuropsychopharmacol 30: 2169-2179.

Lieben, CK, Blokland, A, Westerink, B, Deutz, NE (2004a) Acute tryptophan and serotonin depletion using an optimized tryptophan-free protein-carbohydrate mixture in the adult rat. Neurochem Int 44: 9-16.

Lieben, CK, van Oorsouw, K, Deutz, NE, Blokland, A (2004b) Acute tryptophan depletion induced by a gelatin-based mixture impairs object memory but not affective behavior and spatial learning in the rat. Behav Brain Res 151: 53-64.

Luciana, M, Burgund, ED, Berman, M, Hanson, KL (2001) Effects of tryptophan loading on verbal, spatial and affective working memory functions in healthy adults. J Psychopharmacol 15: 219-230.

McNair, DM, Lorr, M, Droppleman, LF (1971) Manual for the profile of mood states. Educational and Industrial Testing Service: San Diego.

Meneses, A (1999) 5-HT system and cognition. Neurosci Biobehav Rev 23: 1111-1125.

Moore, P, Landolt, HP, Seifritz, E, Clark, C, Bhatti, T, Kelsoe, J, Rapaport, M, Gillin, JC (2000) Clinical and physiological consequences of rapid tryptophan depletion. Neuropsychopharmacol 23: 601-622.

Moscovitch, M, Nadel, L, Winocur, G, Gilboa, A, Rosenbaum, RS (2006) The cognitive neuroscience of remote episodic, semantic and spatial memory. Curr Opin Neurobiol 16: 179-190.

Murphy, FC, Smith, KA, Cowen, PJ, Robbins, TW, Sahakian, BJ (2002) The effects of tryptophan depletion on cognitive and affective processing in healthy volunteers. Psychopharmacology (Berl) 163: 42-53.

Neumeister, A, Nugent, A, Waldeck, T (2004) Neural and behavioral responses to tryptophan depletion in unmedicated patients with remitted MDD and controls. Arch Gen Psychiatry 61: 765-773.

Park, SB, Coull, JT, McShane, RH, Young, AH, Sahakian, BJ, Robbins, TW, Cowen, PJ (1994) Tryptophan depletion in normal volunteers produces selective impairments in learning and memory. Neuropharmacol 33: 575-588.
Pollack, I, Norman, DA (1964) A non-parametric analysis of recognition experiments. Psychonomic Science 1: 125-126.

Porter, RJ, Phipps, AJ, Gallagher, P, Scott, A, Stevenson, PS, O'Brien, JT (2005) Effects of acute tryptophan depletion on mood and cognitive functioning in older recovered depressed subjects. Am J Geriatr Psychiatry 13: 607-615.

Postma, A, de Haan, EH (1996) What was where? Memory for object locations. Q J Exp Psychol A 49: 178-199.

Rey, A (1964) L'examen clinique en psychologie. Paris: Presses Universitaires de France.

Riedel, WJ, Klaassen, T, Deutz, NE, van Someren, A, van Praag, HM (1999) Tryptophan depletion in normal volunteers produces selective impairment in memory consolidation. Psychopharmacology (Berl) 141: 362-369.

Rogers, RD, Blackshaw, AJ, Middleton, HC, Matthews, K, Hawtin, K, Crowley, C, Hopwood, A, Wallace, C, Deakin, JF, Sahakian, BJ, Robbins, TW (1999) Tryptophan depletion impairs stimulusreward learning while methylphenidate disrupts attentional control in healthy young adults: implications for the monoaminergic basis of impulsive behaviour. Psychopharmacology (Berl) 146: 482-491.

Rubinsztein, JS, Rogers, RD, Riedel, WJ, Mehta, MA, Robbins, TW, Sahakian, BJ (2001) Acute dietary tryptophan depletion impairs maintenance of "affective set" and delayed visual recognition in healthy volunteers. Psychopharmacology (Berl) 154: 319-326.

Schmitt, JA, Jorissen, BL, Sobczak, S, van Boxtel, MP, Hogervorst, E, Deutz, NE, Riedel, WJ (2000) Tryptophan depletion impairs memory consolidation but improves focussed attention in healthy young volunteers. J Psychopharmacol 14: 21-29.

Schmitt, JA, Wingen, M, Ramaekers, JG, Evers, EA, Riedel, WJ (2006) Serotonin and human cognitive performance. Curr Pharm Des 12: 2473-2486.

Scholtissen, B, Verhey, FR, Adam, JJ, Prickaerts, J, Leentjens, AF (2006) Effects of acute tryptophan depletion on cognition, memory and motor performance in Parkinson's disease. J Neurol Sci 248 : 259-265.

Sobczak, S, Riedel, WJ, Booij, I, Aan Het Rot, M, Deutz, NE, Honig, A (2002) Cognition following acute tryptophan depletion: difference between first-degree relatives of bipolar disorder patients and matched healthy control volunteers. Psychol Med 32: 503-515.

Umbricht, D, Vollenweider, FX, Schmid, L, Grüberl, C, Skrabo, A, Huber, T, Koller, R (2003) Effects of the 5-HT2a agonist psilocybin on mismatch negativity generation and AX-continuous performance task: implications for the neuropharmacology of cognitive deficits in schizophrenia. Neuropsychopharmacol 28, 170-181.

Van Asselen, M, Kessels, RP, Kappelle, LJ, Postma, A (2008) Categorical and coordinate spatial representations within objectlocation memory. Cortex 44: 249-256.

Van der Does, AJ (2001). The effects of tryptophan depletion on mood and psychiatric symptoms. J Affect Disord 64: 107-119.

van der Veen, FM, Evers, EA, van Deursen, JA, Deutz, NE, Backes, WH, Schmitt, JA (2006) Acute tryptophan depletion reduces activation in the right hippocampus during encoding in an episodic memory task. Neuroimage 31: 1188-1196.

van Eijk, HM, Rooyakkers, DR, Deutz, NE (1993) Rapid routine determination of amino acids in plasma by high-performance liquid chromatography with a 2-3 microns Spherisorb ODS II column. J Chromatogr 620: 143-148.

Young, SN, Smith, SE, Pihl, RO, Ervin, FR (1985) Tryptophan depletion causes a rapid lowering of mood in normal males. Psychopharmacology (Berl) 87: 173-177. 